\title{
Formação de biofilme em aço inoxidável por Aeromonas hydrophila e Staphylococcus aureus usando leite e diferentes condições de cultivo
}

\author{
Biofilm formation by Aeromonas hydrophila and Staphylococcus aureus \\ on stainless steel using milk and different conditions of cultivation
}

\author{
Cleube Andrade BOARI ${ }^{1}$, Mariana Pereira ALVES ${ }^{1}$, Victor Maximiliano Reis TEBALDI ${ }^{1}$, \\ Taciana Villela SAVIAN ${ }^{1}$, Roberta Hilsdorf PICCOLI ${ }^{1 *}$
}

\begin{abstract}
Resumo
O objetivo desta pesquisa consistiu em avaliar a formação de biofilme em aço inoxidável por Aeromonas hydrophila e Staphylococcus aureus usando leite e diferentes condições de cultivo. As variáveis em estudo consistem no cultivo monoespécie e combinado, dos referidos microrganismos e nas temperaturas de 4,7 e $18{ }^{\circ} \mathrm{C}$. Recipientes contendo $1000 \mathrm{~mL}$ de leite, densidade populacional de $10^{5} \mathrm{UFC}_{\mathrm{mL}}^{-1}$ de cada microrganismo e 10 cupons de aço inoxidável $(10 \times 20 \mathrm{~mm})$ foram lacrados e armazenados, sob agitação de $60 \mathrm{rpm}$, por um período de 10 dias. As análises ocorreram a cada 48 horas. Células sésseis de A.hydrophila e S. aureus foram enumeradas através do plaqueamento seletivo em ágar m-Aeromonas selective e Baird-Parker, respectivamente. Estudos sobre o tempo de geração, enumeração de células planctônicas e observação dos cupons através da microscopia eletrônica de varredura foram conduzidos. S. aureus, em monocultivo, formou biofilme a $18^{\circ} \mathrm{C}$ e a $7{ }^{\circ} \mathrm{C}$. Para $4{ }^{\circ} \mathrm{C}$, foi observado um processo de adesão. A presença de A. hydrophila reduziu o desempenho de S. aureus. Nesta condição de cultivo multiespécie houve formação de biofilme a $18^{\circ} \mathrm{C}$. A. hydrophila, tanto em monocultivo quanto em presença de $S$. aureus, formou biofilme em todas as condições pesquisadas.
\end{abstract}

Palavras-chave: Aeromonas hydrophila; Staphylococcus aureus; biofilme; leite; aço inoxidável; temperatura.

\begin{abstract}
The aim of this research was to verify the capability of biofilm formation on stainless steel by Aeromonas hydrophila and Staphylococcus aureus using milk and different conditions of cultivation. The variables consisted in mono and multi-species cultivation of these microorganisms and in the temperatures of 4,7 and $18^{\circ} \mathrm{C}$. Containers containing $1000 \mathrm{~mL}$ of milk, population density of $10^{5} \mathrm{CFU} \cdot \mathrm{mL}^{-1}$ of each microorganism, and ten suspended chips of stainless steel AISI $304(10 \times 20 \mathrm{~mm})$ were used to seal up and storage, under $60 \mathrm{rpm}$ of agitation for 10 days. The analyses were conducted every 48 hours. Sessile cells of A. hydrophila and S. aureus and were enumerated by plating in $\mathrm{m}$-Aeromonas selective agar and Baird-Parker agar. Complementary studies included the generation time calculation, enumeration of planktonic cells, and visualization of chips by scanning electron microscopy. S. aureus, in mono-cultivation, formed biofilm at $18^{\circ} \mathrm{C}$ and at $7{ }^{\circ} \mathrm{C}$. At $4{ }^{\circ} \mathrm{C}$ was observed attachment. The presence of $A$. hydrophila reduced the performance of $S$. aureus. In this condition, S. aureus formed biofilm at $18^{\circ} \mathrm{C}$. A. hydrophila formed biofilm under all conditions.

Keywords: Aeromonas hydrophila; Staphylococcus aureus; biofilm; milk; stainless steel; temperature.
\end{abstract}

\section{Introdução}

Biofilmes correspondem a comunidades constituídas por células sésseis, mono ou multiespécies, aderidas a um substrato, embebidas em uma matriz de polímeros extracelulares (exopolissacarídeos - EPS), em cuja formação os microrganismos exibem diferenciados fenótipos, metabolismo, fisiologia e transcrição genética. (DONLAN; COSTERTON, 2002). Como etapas importantes para a sua formação, são descritas as adesões iniciais, passando os microrganismos de seu estilo de vida planctônico ao séssil, à formação de microlônias, à maturação e ao destacamento de células, retornando estas a seu estilo de vida planctônico (Figura 1 e Figura 2).

Estas estruturas naturalmente ocorrem em variados tipos de ambientes, sejam eles bióticos ou abióticos. Entretanto, afora a sua ocorrência natural, pesquisas sobre a sua formação em superfícies utilizadas na produção de alimentos, como aço inoxidável American Iron and Steel Institute - AISI 304 (2008), vêm recebendo destaque, principalmente no que se refere aos malefícios de sua presença. Uma vez constituídos, os biofilmes agem como pontos de contaminação constante, liberando células de microrganismos patogênicos e/ou deterioradores, como Staphylococcus aureus e Aeromonas hydrophila, podendo comprometer, assim, a qualidade microbiológica de matérias-primas, produtos pré-acabados e acabados (FUSTER-VALLS et al., 2008). As negatividades de sua ocorrência também se relacionam à corrosão de equipamentos, usualmente designada pela expressão Corrosão Microbiologicamente Influenciada (MIC), e pela redução da capacidade da troca de calor entre superfícies (MANSFELD, 2007).

Seguindo à hipótese de que na natureza a constituição destas comunidades oferecia proteção aos indivíduos, o mesmo

${ }^{1}$ Departamento de Ciência dos Alimentos, Universidade Federal de Lavras - UFLA, Campus Universitário, CP 3037, CEP 37200-000, Lavras - MG, Brasil, E-mail: rhpiccoli@dca.ufla.br 
se estende a plantas de produção de alimentos. Tal observação é feita, pois os microrganismos em seu estilo de vida séssil resistem significativamente mais aos agentes empregados nos procedimentos de higienização. Alguns pesquisadores discutem que estas células sejam quinhentas (COSTERTON et al., 1995) ou até mil vezes (DRENKARD, 2003) mais resistentes que as células planctônicas. Um dos grandes responsáveis por conferir esta proteção seria a rede de EPS, que age como barreira

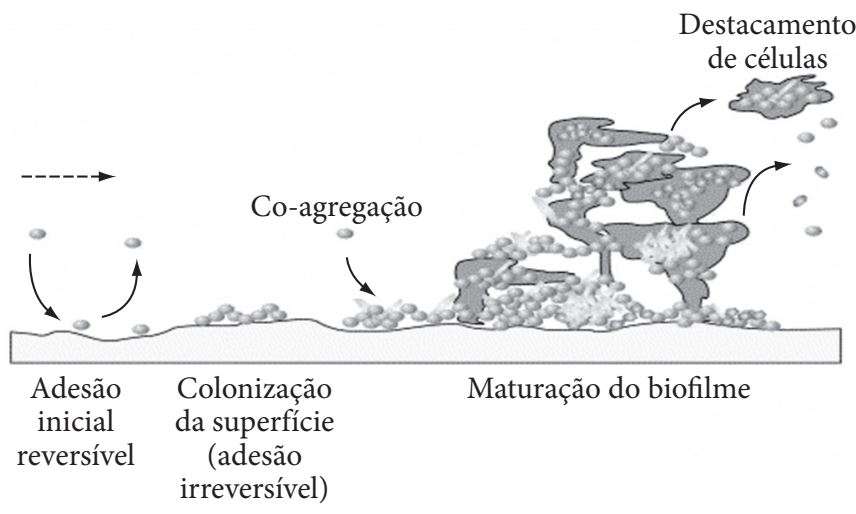

Figura 1. Ciclo de desenvolvimento de um biofilme (Adaptado de JENKINSON; LAPPIN-SCOTT, 2001).

Colonizadores primários

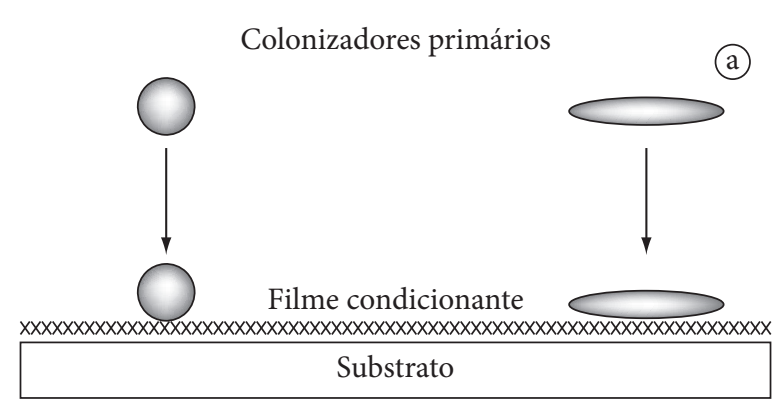

(a)

Colonizadores secundários

(c)

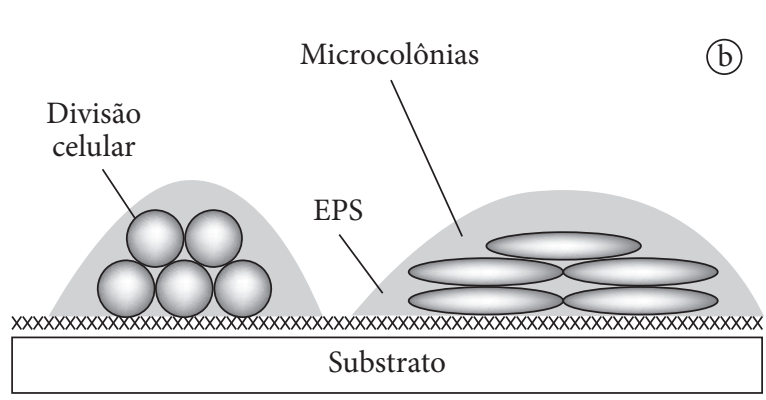

física, impedindo que os agentes sanitizantes cheguem a seus sítios de ação, como, por exemplo, à membrana externa em Gram-negativos. O EPS é também capaz de adsorver cátions, metais e toxinas e conferir proteção contra radiações $U V$, alterações de $\mathrm{pH}$, choques osmóticos e dessecação.

Devido a este agravante, conhecer as condições que propiciam a sua formação e as suas fragilidades é primordial para que estratégias de controle, mais econômicas e eficazes, sejam dimensionadas para a eliminação de mais esta possibilidade de introdução de microrganismos na cadeia alimentar (HERRERA et al., 2007).

Diante do exposto esta investigação foi conduzida com o objetivo de avaliar a capacidade de formação de biofilme em aço inoxidável por Aeromonas hydrophila e Staphylococcus aureus, utilizando-se leite e diferentes condições de cultivo.

\section{Material e métodos}

A. hydrophila e $S$. aureus, isolados de amostras de leite cru na região de Lavras, Minas Gerais, foram inoculados em leite desnatado esterilizado em densidade populacional de $10^{5}$ UFC.mL ${ }^{-1}$. Este valor foi selecionado levando-se em consideração o histórico de isolamento destes microrganismos no leite cru na referida região.
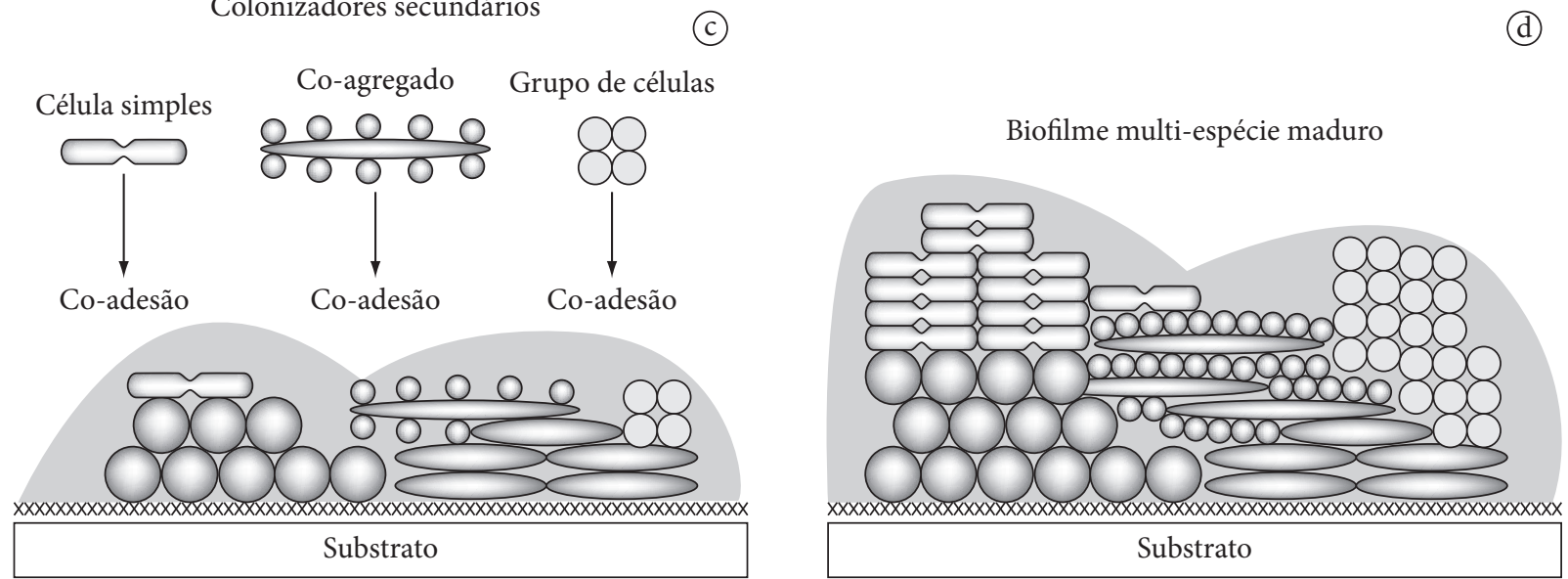

Figura 2. Diagrama ilustrando as etapas de formação de um biofilme multiespécie. a) Colonização primária da superfície, recoberta por um filme condicionante composto por polissacarídeos, proteínas, lipídeos, dentre outros; b) desenvolvimento, divisão celular, síntese de EPS e composição das microcolônias; c) coadesão de células simples e ou coagregados de células e ou grupo de microrganismos; e d) maturação e formação de mosaicos clonais em um biofilme multiespécie. (Adaptado de RICKARD et al., 2003). 
Para a avaliação da capacidade de formação de biofilmes em monocultivo, cada um destes inóculos foi transferido, individualmente, para recipientes contendo $1000 \mathrm{~mL}$ de leite desnatado esterilizado. Para avaliar o seu desempenho em formar biofilmes em cultivo combinado, foram inoculados conjuntamente. A seleção por um isolado Gram-negativo e outro Gram-positivo ocorreu devido a peculiaridades estruturais específicas de cada um destes grupos, capazes de influenciar na adesão e formação de biofilmes, como discutido adiante.

Em cada recipiente, foram adicionados uma barra magnética e 10 cupons de aço inoxidável AISI $304(10 \times 20 \mathrm{~mm})$, mantidos em suspensão por uma estrutura metálica desenvolvida para tal fim. Depois de lacrados, estes sistemas foram armazenados em incubadora $\mathrm{BOD}$ por um período de 10 dias, nas temperaturas de 4,7 e $18{ }^{\circ} \mathrm{C}$, em agitação constante de $60 \mathrm{rpm}$, buscando simular o fluxo de um tanque de expansão por refrigeração. $\mathrm{Na}$ Figura 3, é apresentado um esquema da referida estrutura.

A cada 48 horas, contadas a partir da inoculação, foram coletados 2 cupons (duplicata), sendo os recipientes, o leite e a barra magnética, substituídos.

Para a enumeração das células sésseis a cada um dos cupons, previamente rinsados em água peptonada para remoção de resíduos de leite e células não aderidas, foi aplicada a técnica de esfregaço de superfície, com o auxílio de swabs. S. aureus foram quantificados empregando-se o plaqueamento seletivo em ágar Baird-Parker (Biolife, Milão, Itália), com incubação a $37^{\circ} \mathrm{C} / 24-48$ horas (VANDERZANT; SPLITTSTOESSER, 1992). A. hydrophila foi enumerada através do plaqueamento em m-Aeromonas Selective Agar Haavelar (Biolife, Milão, Itália), com adição de ampilicina (10 mg. $\left.\mathrm{L}^{-1}\right)$ e incubação a $28^{\circ} \mathrm{C} / 24-48$ horas (PALUMBO et al., 1985).

A fim de se diferenciar o que seria um processo de adesão ou um biofilme, foi considerado o valor de $10^{5} \mathrm{UFC} / \mathrm{cm}^{2}$, sendo este intermediário ao proposto por Andrade, Bridgeman e Zottola (1998), que estabelecem o valor de $10^{7} \mathrm{UFC} / \mathrm{cm}^{2}$, e ao apresentado por Wirtanen, Husmark e Mattila-Sandholm (1996)

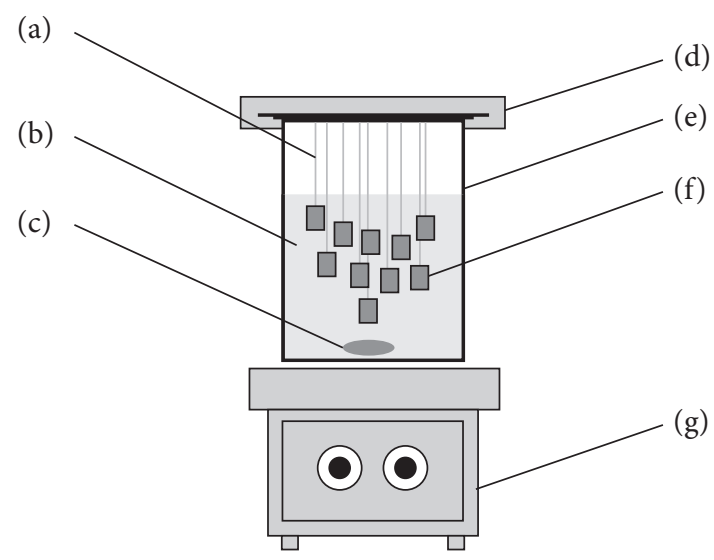

Figura 3. Estrutura para o estudo da formação de biofilme: a) fio de náilon; b) leite desnatado esterilizado; c) barra magnética; d) placa de Petri e filme PVC para lacrar o sistema; e) recipiente; f) cupom de aço inoxidável AISI $304 \mathrm{com} 1 \mathrm{~cm}^{2}$ de área por face; e g) agitador magnético regulado a $60 \mathrm{rpm}$. e Ronner e Wong (1993), que consideram como biofilme um número de células aderidas de $10^{3}$ e $10^{5}$ células por $\mathrm{cm}^{2}$.

\subsection{Investigações complementares}

\section{Quantificação de células planctônicas na fase aquosa - o leite}

No momento em que ocorreram as trocas, $1,0 \mathrm{~mL}$ de leite utilizado no cultivo foi coletado para a enumeração das células planctônicas, seguindo o protocolo para plaqueamento e incubação já apresentado para a quantificação das células sésseis.

\section{Tempo de geração}

O tempo de geração de S. aureus e A. hydrophila, nas condições experimentais, foi conduzido através da sua inoculação a densidades populacionais conhecidas, em crescimento logarítmico, em recipientes contendo $1000 \mathrm{~mL}$ de leite desnatado esterilizado. Em dez pontos, durante a fase de crescimento exponencial, alíquotas de 1,0 mL foram coletadas, submetidas a diluições seriadas e plaqueadas em ágar Baird-Parker e m-Aeromonas selective Haavelar, como descrito anteriormente.

\section{Microscopia eletrônica de varredura (MEV)}

A preparação dos cupons para a sua observação através da microscopia eletrônica de varredura seguiu o protocolo proposto por Alves (2004) e Bossola e Russell (1998). Todos estes procedimentos foram conduzidos no Laboratório de Microscopia Eletrônica e Análise Ultraestrutural da Universidade Federal de Lavras, UFLA.

\subsection{Sobre as condições experimentais}

O uso do leite desnatado se deve ao fato de que os lipídios, presentes no leite integral, poderiam favorecer a adesão e a formação de biofilmes, superestimando-se, assim, a real capacidade do microrganismo. As temperaturas de $4 \mathrm{e}$ $7^{\circ} \mathrm{C}$ foram selecionadas com base na legislação vigente para a qualidade do leite a granel (BRASIL, 1996; 2002). A temperatura de $18{ }^{\circ} \mathrm{C}$ foi escolhida, pois este valor pode ser alcançado em função da incorporação de leite recém-ordenhado ao tanque de expansão e sua mistura com leite previamente armazenado e, porventura, já resfriado. O período para substituição do leite nos recipientes, a cada 48 horas, foi dimensionando de acordo com a legislação vigente para a qualidade do leite cru, que estabelece este como sendo o tempo máximo entre a ordenha e o recebimento do leite cru no estabelecimento onde será processado (BRASIL, 1996; 2002). O aço inoxidável AISI 304 foi selecionado como substrato à adesão e à formação de biofilme, visto ser esta a superfície mais empregada em plantas de produção de alimentos (HOOD; ZOTTOLA, 1997).

\subsection{Delineamento estatístico}

$\mathrm{O}$ experimento foi instalado segundo um delineamento inteiramente casualizado com duas repetições, nas quais os 
tratamentos foram arranjados em parcela subdividida no tempo. Os tratamentos de parcela foram dimensionados em esquema fatorial $2 \times 3$ (dois tipos de cultivo: mono e multiespécie; três temperaturas: 4,7 e $18{ }^{\circ} \mathrm{C}$ ), sendo analisados ao longo de 10 dias, a cada 48 horas (2, 4, 6, 8 e 10 dias). Os dados obtidos foram analisados pelo programa estatístico SAS (1995), sendo realizado o teste de Tukey com nível nominal de significância de $5 \%$ e análise de regressão.

\section{Resultados e discussão}

\subsection{Tempo de geração}

Os tempos de geração, em minutos, para A. hydrophila e S. aureus, em leite desnatado esterilizado, a 4,7 e $18^{\circ} \mathrm{C}$ são apresentados na Tabela 1 .

Observa-se que, o maior tempo de geração de A. hydrophila (50 minutos em $4{ }^{\circ} \mathrm{C}$ ) coincide com o menor resultado para S. aureus (50 minutos em $18{ }^{\circ} \mathrm{C}$ ). A. hydrophila, em todas as temperaturas estudadas, exibiu um desempenho superior ao $S$. aureus e este fator pode colaborar com a sua maior prevalência no biofilme. De acordo com Banks e Bryers (1991), a dominância de determinadas espécies microbianas em um biofilme estão intimamente relacionadas com a sua taxa de crescimento e reprodução.

A temperatura é considerada como um dos fatores intrínsecos mais importantes e capazes de influenciar o desenvolvimento bacteriano. Neste contexto, a elevação no tempo de geração, percebida tanto de $S$. aureus quanto A. hydrophila, em resposta ao abaixamento da temperatura se explica, principalmente, em função da redução da cinética de reação das enzimas. Quanto mais afastados de seu ótimo, menor a taxa metabólica e, consequentemente, menor a taxa de reprodução.

\subsection{Formação de biofilme por Staphylococcus aureus}

$\mathrm{Na}$ Figura 4, são apresentadas as curvas da quantidade de células sésseis de $S$. aureus, expressas em $\log \mathrm{UFC} / \mathrm{cm}^{2}$, para os tempos e temperaturas estudadas, tanto em monocultivo (S), quanto em presença de A. hydrophila (S/A).

\section{Desempenho de Staphylococcus aureus em mono-cultivo}

$\mathrm{Na}$ condição de monocultivo e a $18^{\circ} \mathrm{C}$, houve formação de biofilme por $S$. aureus nas primeiras 48 horas. A $7^{\circ} \mathrm{C}$ tal fato ocorreu após 4 dias, indicando que a redução da temperatura afetou seu desempenho. Para ambas as temperaturas, foi observada uma tendência linear de aumento de células sésseis ao longo dos 10 dias pesquisados, chegando estas a valores de

Tabela 1. Tempo de geração, em minutos, para Aeromonas hydrophila e Staphylococcus aureus, a 4,7 e $18^{\circ} \mathrm{C}$, em leite desnatado esterilizado.

\begin{tabular}{lccc}
\hline & \multicolumn{3}{c}{ Tempo de geração } \\
\hline & $4^{\circ} \mathrm{C}$ & $7{ }^{\circ} \mathrm{C}$ & $18{ }^{\circ} \mathrm{C}$ \\
\hline Aeromonas hydrophila & 50 & 47 & 41 \\
Staphylococcus aureus & 61 & 58 & 50 \\
\hline
\end{tabular}

$1,7 \times 10^{8} \mathrm{UFC} / \mathrm{cm}^{2}$ e $2,5 \times 10^{7} \mathrm{UFC} / \mathrm{cm}^{2}$, respectivamente. De acordo com Stoodley et al. (2002), este aumento de células faz parte do próprio processo de maturação do biofilme, podendo compreender até dez dias após a adesão inicial. Segundo estes autores, a elevação na densidade populacional decorre da divisão celular e da coadesão de outras células.

Não foi observada a formação de biofilme a $4{ }^{\circ} \mathrm{C}$, caracterizando-se um processo de adesão microbiana. Nesta temperatura foi constatado o pior desempenho de $S$. aureus ( $\mathrm{p}<0,005)$, sendo o número máximo de células sésseis, aos 10 dias, de $3,7 \times 10^{4} \mathrm{UFC} / \mathrm{cm}^{2}$. Este fato, em condições práticas, nos aponta que esta temperatura, empregada em tanques de expansão por refrigeração, seria uma alternativa à redução da formação de biofilmes por S. aureus. Entretanto, não deve ser cometida a ingenuidade de menosprezar os malefícios do processo de adesão.

Desempenho de Staphylococcus aureus em cultivo com Aeromonas hydrophila

Em se tratando do cultivo combinando com A. hydrophila, foi observada a formação de biofilme por $S$. aureus apenas a $18^{\circ} \mathrm{C}$, a partir do quarto dia. O número de células planctônicas, neste caso, foi de $5,7 \times 10^{6} \mathrm{UFC} / \mathrm{cm}^{2}$, ou seja, aproximadamente dois ciclos logarítmicos inferior ao biofilme monoespécie.

Para a temperatura de $7^{\circ} \mathrm{C}$, na qual foi observada a formação de biofilme por $S$. aureus, em monocultivo, não foi observado o mesmo comportamento quando em cultivo combinado. Analisando-se o tempo de geração, percebe-se que $A$. hydrophila apresenta um desempenho reprodutivo superior ao $S$. aureus, podendo, assim, delimitar a sua adesão por competição.
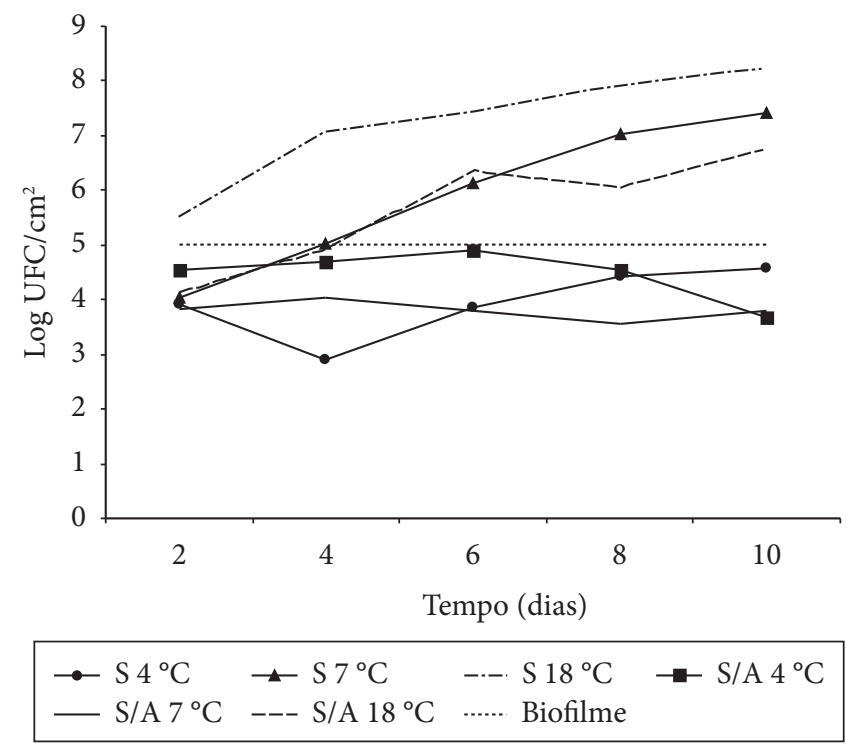

Figura 4. Contagem de células sésseis de Staphylococcus aureus presentes em cupons de aço inoxidável AISI 304, ao longo de 10 dias, para as temperaturas de 4,7 e $18^{\circ} \mathrm{C}$, nas condições de mono-cultivo (S) e na presença de Aeromonas hydrophila (S/A). 
A $4{ }^{\circ} \mathrm{C}$, repetindo o resultado do cultivo monoespécie, apenas foi observado um processo de adesão de $S$. aureus, não havendo diferença significativa $(\mathrm{p}<0,05)$ entre a performance de $S$. aureus monoespécie ou em presença de A. hydrophila. No sexto dia, foi observada uma quantidade de células aderidas de $S$. aureus suficiente para classificar sua presença como biofilme $\left(1,2 \times 10^{5} \mathrm{UFC} / \mathrm{cm}^{2}\right)$, que, no entanto, se reduziu a $3,5 \times 10^{4} \mathrm{UFC} / \mathrm{cm}^{2}$ no oitavo dia e a $4,7 \times 10^{3} \mathrm{UFC} / \mathrm{cm}^{2}$, no décimo dia.

De acordo com Oulahal et al. (2008), S. aureus, embora seja um microrganismo mesofílico, ou seja, com temperatura ótima a seu desenvolvimento em torno de $37^{\circ} \mathrm{C}$, é capaz de sobreviver em temperaturas empregadas na refrigeração de alimentos, sem, no entanto, apresentar bom crescimento. A informação destes pesquisadores coincide com o encontrado nesta pesquisa.

Aos $18{ }^{\circ} \mathrm{C}$, em presença de A. hydrophila, S. aureus formou biofilme no sexto dia, com aproximados $2,2 \times 10^{6} \mathrm{UFC} / \mathrm{cm}^{2}$. Na condição de monocultivo, $S$. aureus, nesta temperatura, havia formado biofilme no segundo dia.

O maior número de células sésseis de $S$. aureus, em monocultivo, foi encontrado nas condições $18{ }^{\circ} \mathrm{C} / 10$ dias, sendo este de $1,7 \times 10^{8} \mathrm{UFC} / \mathrm{cm}^{2}$, e o maior número, em cultivo combinado com $A$. hydrophila, a $18{ }^{\circ} \mathrm{C} / 10$ dias, de $5,7 \times 10^{5} \mathrm{UFC} / \mathrm{cm}^{2}$, sendo quase três ciclos logarítmicos inferior.

Pompermayer e Gaylarde (2000), em sua pesquisa sobre a adesão de $S$. aureus e Escherichia coli, em condição de monocultivo e cultivo combinado, concluíram que o melhor desempenho de $S$. aureus aconteceu em culturas monoespécies. Segundo estes pesquisadores, há uma superioridade de microrganismos Gram-negativos em se aderir e formar biofilmes devido aos aparatos celulares por eles apresentados, como flagelos, bem como o seu menor tempo de geração, o que garante a sua dominância, em relação a Gram-positivos.

\subsection{Formação de biofilme por Aeromonas hydrophila}

Na Figura 5, são apresentadas as curvas da quantidade de células sésseis de A. hydrophila, expressas em $\log \mathrm{UFC} / \mathrm{cm}^{2}$, para os tempos e temperaturas estudadas, tanto em monocultivo (A), quanto em presença de S. aureus (A/S).

\section{Desempenho de Aeromonas hydrophila em monocultivo}

A. hydrophila formou biofilme em todas as condições investigadas, sendo que, para 7 e $18{ }^{\circ} \mathrm{C}$ já o haviam formado no segundo dia, com contagens de $1,4 \times 10^{5} \mathrm{UFC} / \mathrm{cm}^{2} \mathrm{e}$ $4,7 \times 10^{5} \mathrm{UFC} / \mathrm{cm}^{2}$, respectivamente. Para $4{ }^{\circ} \mathrm{C}$, foi observado biofilme a partir de 4 dias, com $1,7 \times 10^{5} \mathrm{UFC} / \mathrm{cm}^{2}$.

Não houve diferença significativa $(\mathrm{p}<0,05)$ entre 4 e $7{ }^{\circ} \mathrm{C}$, ao longo dos tempos estudados. O melhor desempenho foi observado a $18{ }^{\circ} \mathrm{C}$, no qual, aos dez dias, foram quantificadas $2,2 \times 10^{10} \mathrm{UFC} / \mathrm{cm}^{2}$.

Para todas as temperaturas, foi observada uma tendência linear de aumento de células sésseis no biofilme.
Desempenho de Aeromonas hydrophila em cultivo com Staphylococcus aureus

Para 4 e $7{ }^{\circ} \mathrm{C}$, não houve diferença significativa $(\mathrm{p}<0,05)$ entre o desempenho de A. hydrophila em monocultivo ou em presença de $S$. aureus. Em tais condições também houve uma tendência linear no aumento de células planctônicas. Entretanto, para $18^{\circ} \mathrm{C}$, a partir do sexto dia foi observada uma redução na quantidade de células de A. hydrophila aderidas, em função da presença de $S$. aureus. Tal fato pode ter ocorrido, pois S. aureus, na medida em que se aproxima de sua temperatura ótima, tem sua taxa metabólica aumentada, o que colabora de forma mais representativa para o consumo de nutrientes do meio, o que prejudicaria o desempenho da A. hydrophila. Segundo Sawyer e Hermanowicz (1998), a depleção de nutrientes é um dos fatores que desestimula a formação de biofilme por A. hydrophila e, além disto, é interpretada como sinal positivo ao destacamento de células.

O melhor desempenho de A. hydrophila foi observado na condição de cultivo monoespécie a $18^{\circ} \mathrm{C}$, no qual foi constatada uma quantidade de células planctônicas de $9,5 \times 10^{10} \mathrm{UFC} / \mathrm{cm}^{2}$. A $4{ }^{\circ} \mathrm{C}$, tanto em cultivo monoespécie, quanto em cultivo combinado, não foi observada a formação de biofilme nas primeiras 48 horas, sendo que, para as demais condições, o valor de $10^{5} \mathrm{UFC} / \mathrm{cm}^{2}$ já havia sido ultrapassado neste tempo. Uma interpretação prática deste fato seria que, caso o tanque de expansão por refrigeração não seja adequadamente higienizado a cada dois dias, será possível a formação de biofilmes por A. hydrophila, o que dificultaria a sua posterior eliminação devido aos mecanismos de proteção do EPS.

A combinação de $S$. aureus e $A$. hydrophila reduziu a performance deste segundo microrganismo, comparando-se a quantidade de células no estado séssil aos 10 dias. A redução

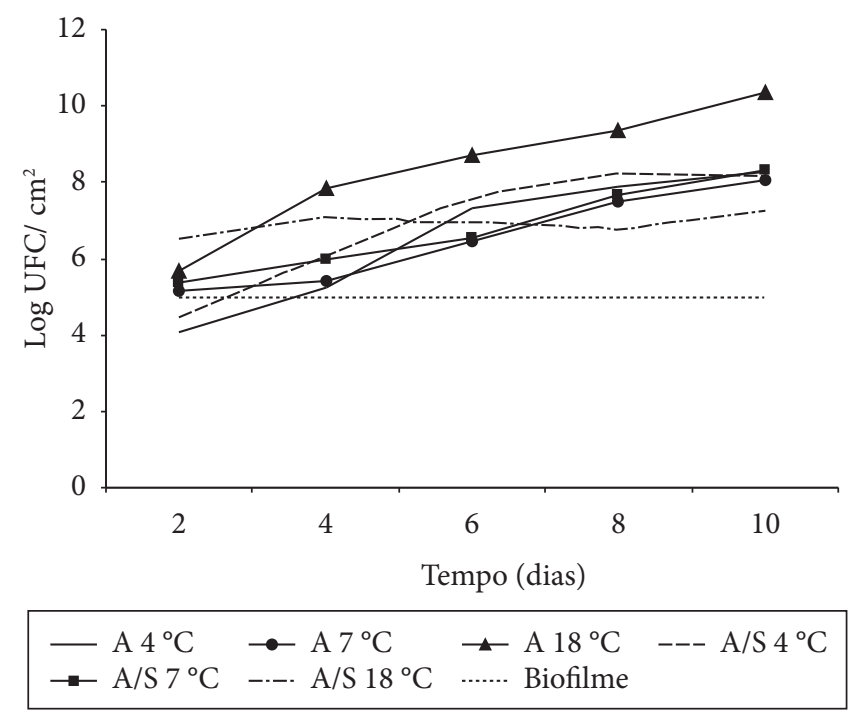

Figura 5. Contagem de células sésseis de Aeromonas hydrophila presentes em cupons de aço inoxidável AISI 304, ao longo de 10 dias, para as temperaturas de 4,7 e $18^{\circ} \mathrm{C}$, nas condições de mono-cultivo (A) e na presença de Staphylococcus aureus (A/S). 
foi de, aproximadamente, três ciclos logarítmicos, com valor de $1,7 \times 10^{7} \mathrm{UFC} / \mathrm{cm}^{2}$.

$\mathrm{Na}$ Tabela 2, são apresentadas as contagens em $\mathrm{UFC} / \mathrm{cm}^{2} \mathrm{e}$ as percentagens de cada um dos microrganismos, no biofilme multiespécie maduro (10 dias), para cada uma das temperaturas avaliadas.

Para as temperaturas de 4 e $7{ }^{\circ} \mathrm{C}$, nas quais não houve formação de biofilme por $S$. aureus em cultivo combinado, a sua participação, em total de células sésseis, foi de $0,0033 \%$, em comparação com os $99,99 \%$ de A. hydrophila. Aos $18^{\circ} \mathrm{C}$ e em cultivo com A. hydrophila, houve a formação de biofilme por $S$. aureus e sua maior participação no total de células sésseis, chegando a $24,9 \%$. Tais dados reforçam o que se discute sobre as vantagens de Gram-negativos sobre Gram-positivos no processo de colonização e formação de biofilme.

\subsection{A quantificação de células planctônicas no leite}

Na Tabela 3 são apresentadas as contagens de células planctônicas no leite, ao longo do tempo e das condições

Tabela 2. Participação de Staphylococcus aureus e Aeromonas hydrophila, em UFC/ $\mathrm{cm}^{2}$ e sua percentagem, em biofilme multiespécie maduro (10 dias), nas temperaturas de 4,7 e $18^{\circ} \mathrm{C}$.

\begin{tabular}{ccccc}
\hline & & S. aureus & A. hydrophila & Total \\
\hline $4{ }^{\circ} \mathrm{C}$ & $\mathrm{UFC} / \mathrm{cm}^{2}$ & $4,7 \times 10^{7}$ & $1,4 \times 10^{8}$ & $1,4 \times 10^{7}$ \\
& $\%$ & $0,0033 \%$ & 99,9967 & $100 \%$ \\
$7{ }^{\circ} \mathrm{C}$ & $\mathrm{UFC} / \mathrm{cm}^{2}$ & $6,3 \times 10^{3}$ & $2,0 \times 10^{8}$ & $2,0 \times 10^{8}$ \\
& $\%$ & $0,0031 \%$ & 99,9969 & $100 \%$ \\
$18^{\circ} \mathrm{C}$ & $\mathrm{UFC} / \mathrm{cm}^{2}$ & $5,8 \times 10^{6}$ & $1,7 \times 10^{7}$ & $2,3 \times 10^{7}$ \\
& $\%$ & $24,9 \%$ & $75,1 \%$ & $100 \%$ \\
\hline
\end{tabular}

Tabela 3. Valores médios para a contagem de células planctônicas no leite desnatado esterilizado, expressos em log UFC. $\mathrm{mL}^{-1}$, observados nas condições de mono-cultivo e cultivo combinado de Staphylococcus aureus e Aeromonas hydrophila, ao longo do tempo e nas temperaturas de 4,7 e $18{ }^{\circ} \mathrm{C}$.

\begin{tabular}{|c|c|c|c|c|c|c|}
\hline & \multicolumn{6}{|c|}{ Tempo (dias)/área $\mathrm{cm}^{2}$} \\
\hline & $\begin{array}{c}\text { Inoc. }^{5} \\
20 \mathrm{~cm}^{2}\end{array}$ & $\begin{array}{c}2 \\
20 \mathrm{~cm}^{2} \\
\end{array}$ & $\begin{array}{c}4 \\
16 \mathrm{~cm}^{2}\end{array}$ & $\begin{array}{c}6 \\
12 \mathrm{~cm}^{2} \\
\end{array}$ & $\begin{array}{c}8 \\
8 \mathrm{~cm}^{2} \\
\end{array}$ & $\begin{array}{c}10 \\
4 \mathrm{~cm}^{2} \\
\end{array}$ \\
\hline $\mathrm{S}^{1} 4{ }^{\circ} \mathrm{C}$ & 5 & 6,51 & 6,4 & 6,32 & 6,54 & 6,0 \\
\hline $\mathrm{S} 7{ }^{\circ} \mathrm{C}$ & 5 & 6,44 & 6,55 & 6,72 & 6,19 & 6,9 \\
\hline $\mathrm{S} 18^{\circ} \mathrm{C}$ & 5 & 7,5 & 7,25 & 7,34 & 7,9 & 7,5 \\
\hline $\mathrm{S} / \mathrm{A}^{2} 4^{\circ} \mathrm{C}$ & 5 & 6,6 & 6,32 & 5,88 & 5,22 & 6,17 \\
\hline $\mathrm{S} / \mathrm{A} 7{ }^{\circ} \mathrm{C}$ & 5 & 6,7 & 5,07 & 6,13 & 6,38 & 6,47 \\
\hline $\mathrm{S} / \mathrm{A} 18^{\circ} \mathrm{C}$ & 5 & 7,0 & 7,1 & 6,0 & 6,69 & 6,14 \\
\hline $\mathrm{A}^{3} 4^{\circ} \mathrm{C}$ & 5 & 6,59 & 6,56 & 7,22 & 6,28 & 6,55 \\
\hline A $7^{\circ} \mathrm{C}$ & 5 & 6,69 & 6,61 & 7,12 & 6,84 & 6,6 \\
\hline A $18^{\circ} \mathrm{C}$ & 5 & 7,79 & 7,28 & 7,42 & 7,59 & 7,5 \\
\hline $\mathrm{A} / \mathrm{S}^{4} 4^{\circ} \mathrm{C}$ & 5 & 6,8 & 5,8 & 6,1 & 6,24 & 6,8 \\
\hline $\mathrm{A} / \mathrm{S} 7{ }^{\circ} \mathrm{C}$ & 5 & 6,92 & 6,6 & 5,98 & 6,37 & 3,66 \\
\hline $\mathrm{A} / \mathrm{S} 18^{\circ} \mathrm{C}$ & 5 & 7,4 & 6,32 & 6,47 & 6,61 & 7,2 \\
\hline Média & 5 & 6,9 & 6,48 & 6,56 & 6,57 & 6,46 \\
\hline
\end{tabular}

estudadas. Para cada cupom foi considerada uma área de $2 \mathrm{~cm}^{2}$, pois, por serem mantidos em suspensão, exibiam duas faces de contato com o leite.

Observa-se que, dois dias após a inoculação de $10^{5} \mathrm{UFC} \cdot \mathrm{mL}^{-1}$ a contagem de células planctônicas de $S$. aureus e A. hydrophila, tanto em monocultivo quanto cultivo combinado, estava em torno de $10^{6}$ ou $10^{7}$ UFC. $\mathrm{mL}^{-1}$ de leite, sendo em média 6,9. Para os demais tempos, houve, também, uma tendência à presença de células planctônicas no intervalo de $10^{6}$ e $10^{7}$ UFC. $\mathrm{mL}^{-1}$.

É interessante salientar que, mesmo havendo a troca do leite dos béqueres e barras magnéticas por outros esterilizados e a retirada de dois cupons (redução gradativa de $4 \mathrm{~cm}^{2}$ de contato a cada dia de análise), a contagem destes microrganismos no leite, a princípio nula, atingiu um patamar relativamente constante, de zero a $10^{6}-10^{7}$ UFC. $\mathrm{mL}^{-1}$, a cada dois dias, independente da condição de cultivo.

\subsection{Eletromicrografias de varredura}

Na Figura 6 são apresentadas as eletromicrografias geradas por microscopia eletrônica de varredura (MEV).

\subsection{Os microrganismos Staphylococcus aureus e Aeromonas hydrophila}

A opção por se pesquisar a formação de biofilmes por S. aureus se deve ao fato da clássica presença deste Gram-positivo na cadeia de produção de leite e derivados e em função de suas implicações em questões de saúde pública. Segundo Tirado e Schimidt (2001), em se tratando do cenário epidemiológico mundial, estes microrganismos são considerados como a terceira mais relevante causa de doenças transmitidas por alimentos. Sua entrada na cadeia de leite pode acontecer através da matéria-prima contaminada, visto que microrganismos desta espécie são um dos agentes etiológicos da mastite bovina (OLIVEIRA et al., 2007). Outra importante fonte de contaminação seriam os colaboradores, visto a possibilidade de serem reservatórios naturais desta bactéria. André et al. (2008), em suas pesquisas sobre a prevalência de $S$. aureus em uma unidade de produção de leite e derivados em Goiás, Brasil, detectaram que $75 \%$ de colaboradores, de um total de 140, apresentavam este microrganismo em suas mãos. A sua importância, no que diz respeito à formação de biofilmes, tem sido relatada em pesquisas (HERRERA et al., 2007; RODE et al., 2007)

A seleção por A. hydrophila diz respeito à emergência deste Gram-negativo em questões de segurança e estabilidade de alimentos. Microrganismos desta espécie são psicrotróficos, ou seja, mesmo apresentando como temperatura ótima a seu crescimento algo em torno de $28^{\circ} \mathrm{C}$, são capazes de se desenvolver nas temperaturas empregadas na conservação de alimentos. Desta forma, a refrigeração do leite cru, embora proporcione o controle de microrganismos mesofílicos indesejados, como S. aureus, acaba por favorecer o desenvolvimento de psicrotróficos, como Aeromonas spp. (MARCHAND et al., 2007).

Embora sua participação como agente etiológico de doenças veiculadas por alimentos ainda seja questionada, esta bactéria vem sendo isolada em fezes de indivíduos acometidos 

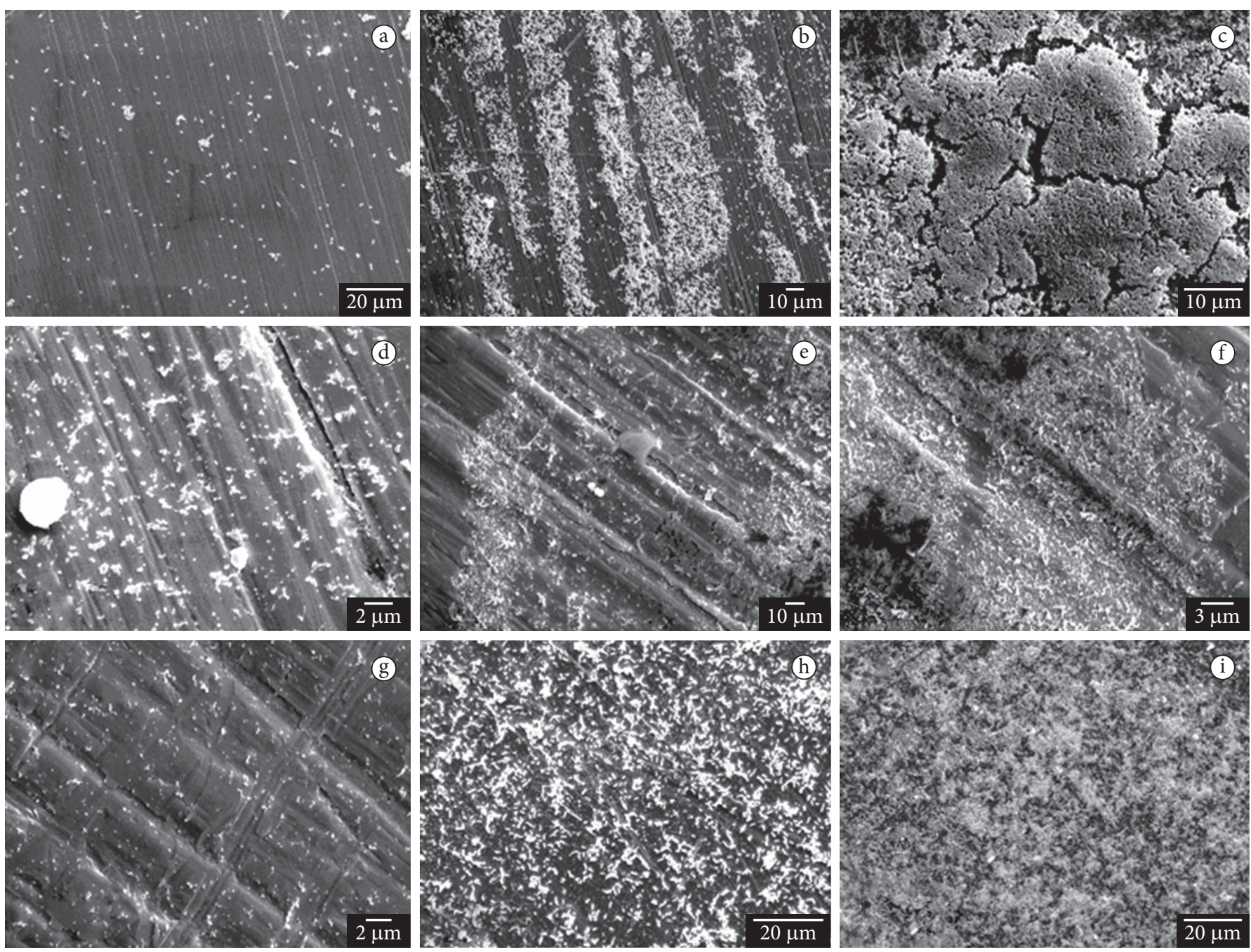

Figura 6. Eletromicrografias de varredura da formação de biofilmes por S. aureus e A. hydrophila em cupons de aço inoxidável AISI 304 à $18^{\circ} \mathrm{C}$. a) A. hydrophila após seis horas de inoculação em leite desnatado esterilizado; b) A. hydrophila após dois dias de contato; c) A. hydrophila após dez dias de contato; d) S. aureus após seis horas de contato; e) S. aureus após dois dias; f) S. aureus após dez dias; g) S. aureus e A. hydrophila em cultivo combinado, após seis horas; h) S. aureus e A. hydrophila em cultivo combinado, após dois dias; e i) S. aureus e A. hydrophila em cultivo combinado após dez dias.

por infecções alimentares. Atualmente, a sua mais destacada importância se refere à sua capacidade de deterioração de alimentos. Microrganismos desta espécie são potenciais produtores de exoenzimas termorresistentes, como lipases e proteases. Estes metabólitos, mesmo tendo a sua estrutura terciária danificada durante o processo de pasteurização, são capazes de reorganizar a sua estrutura tridimensional, tornandose novamente ativos e passíveis de deteriorar os produtos posteriormente obtidos (BRAUN; SUTHERLAND, 2005).

A presença de A. hydrophila, na cadeia de leite e seus derivados, vem sendo documentada (CARNEIRO; ROSSI Jr., 2006; FREITAS et al., 1993). Bulhões e Rossi Junior (2002), ao estudar a prevalência deste microrganismo no queijo-de-minas frescal artesanal, detectaram a sua presença em $51,2 \%$ amostras (82/160), em quantidades que variaram entre 5,0 $\times 10^{3} \mathrm{e} 4,0 \times 10^{5} \mathrm{UFC}^{-1} \mathrm{~g}^{-1}$. Segundo os referidos autores, as precárias condições de higiene no setor primário e o possível uso de água não tratada seriam pontos críticos a sua inserção nesta cadeia produtiva.

\subsection{Consideraçães sobre a adesão inicial de microrganismos no aço inoxidável}

Segundo informações disponíveis no sítio do American Iron and Steel Institute e da British Stainless Steel Association, o aço inoxidável, descoberto por Harry Brearley, Inglaterra, 1912, corresponde a uma liga composta por ferro e cromo. Em se tratando do AISI 304, o mais utilizado na indústria de alimentos, esta liga contém de 18 a $20 \%$ de cromo; 8,0 a $10,5 \%$ de níquel e o restante de ferro.

Por um fenômeno denominado Passivação, o cromo, devido à sua alta afinidade com o oxigênio, tende a se combinar com este formando uma fina camada de óxido de cromo, com aproximados 40 Angstron de espessura. Esta camada passiva é a responsável pela resistência à corrosão e pela hidrofobicidade do aço inoxidável.

Neste contexto, em se tratando da adesão inicial, então, quanto mais hidrofóbica for a célula bacteriana, maior a 
sua capacidade de se ligar diretamente a esta superfície. Considerações semelhantes foram feitas por Sheng, Ting e Pehkonen (2007) e Meylheuc et al. (2006).

Os diferentes graus de hidrofobicidade de uma célula são conferidos por fatores de virulência associados à adesão, como pili, fímbrias e flagelos, bem como pela membrana externa, em gram-negativos, e os diferentes graus de eletronegatividade conferidos pela presença de grupos funcionais polares, como fosfatos, carboxilas, hidroxilas e ácido teicoico (FLACH; KARNOPP; CORÇÃO, 2005; VANHAECKE et al., 1990). Desta forma, bactérias Gram-negativas, devido a suas estruturas peculiares, apresentariam uma vantagem competitiva, quando comparadas a Gram-positivas, no que diz respeito à adesão inicial, colonização da superfície e formação do biofilme.

Com base em considerações feitas durante a condução desta pesquisa, apresentamos, na Figura 7, um modelo para descrever a adesão inicial de microrganismos no aço inoxidável.

Em 7a é apresentada a interação direta entre o microrganismo com a camada passiva. Microrganismos Gram-negativos, potencialmente mais hidrofóbicos, como A. hydrophila, poderiam se aderir dessa forma. Em $7 \mathrm{~b}$ e $7 \mathrm{c}$ é apresentada a interação entre a célula e um filme condicionante. Este filme, constituído por elementos da fase aquosa, como minerais, lipídios e proteínas, poderia intermediar o contato entre microrganismo cuja superfície seja menos hidrofóbica e o aço. Caso estes constituintes tenham caráter anfipático, poderiam se ligar ao aço inox por sua fração apolar e expor seu radical polar, facilitando a adesão do microrganismo. No leite, estes constituintes seriam representados pela lecitina e pela caseína. S. aureus, Gram-positivo e que não apresenta membrana externa ou estruturas para motilidade, como flagelos, tende a ser menos hidrofóbico. Para microrganismos como estes, o filme condicionante pode exercer apoio fundamental a sua adesão.

\subsection{Considerações práticas sobre o ensaio in vitro}

Este ensaio in vitro se baseou na seguinte indagação: quais seriam as consequências do armazenamento de uma quantidade de leite cru contaminado por S. aureus e A. hydrophila em um tanque de refrigeração por expansão, no qual apenas seriam aplicados procedimentos de limpeza, para remoção de resíduos (representados, no ensaio, pela rinsagem dos cupons), sem, no entanto, serem conduzidos procedimentos de sanitização?

Em resposta a este questionamento, S. aureus e A. hydrophila foram capazes de se aderir ao aço inoxidável e formar biofilmes em várias das condições testadas, como anteriormente discutido.

A presença destas bactérias no estado planctônico foi elevada, indicando que, caso um biofilme se forme em um tanque de expansão, poderá haver uma quantidade de células suficientes para alterar as propriedades sensoriais do leite cru e seus derivados, bem como torná-los inseguros ao consumo humano.

A mais eficiente forma de se impedir a formação de um biofilme e a consequente ocorrência de tantos malefícios corresponde à prática constante de adequados procedimentos de higiene industrial, contemplando, não só a remoção de resíduos mas também a eliminação de células indesejáveis, é através da sanitização (CHMIELEWSKI; FRANK, 2003). Conforme relatado por Arcuri (2000), na cadeia de produção de alimentos, há uma correlação positiva entre a falha nos procedimentos de higiene e a formação destes filmes bacterianos, pois, havendo condições, as células aderidas evoluem para microcolônias e assim, posteriormente, ao biofilme maduro. Além disto, a obtenção higiênica do leite e o atendimento a demais itens que compõem as boas práticas de processamento de alimentos são imprescindíveis ao controle destes microrganismos na cadeia alimentar.

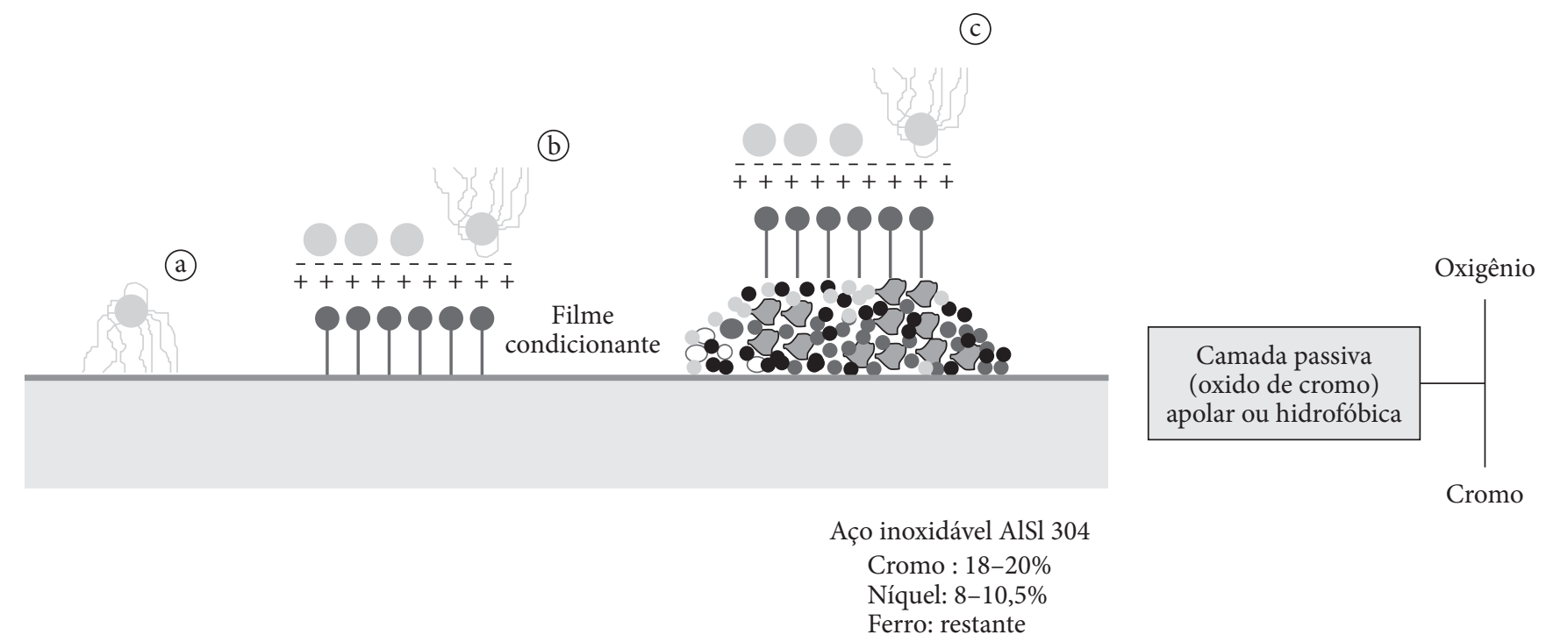

Figura 7. Esquema para a formação da camada passiva e para a adesão inicial de microrganismo diretamente ao aço inoxidável ou à camada ou filme condicionante. Em a) são mostradas as interações hidrofóbicas; e b, c) interações eletrostáticas, com participação do filme condicionante. 


\section{Conclusão}

S. aureus, em monocultivo, formou biofilme a 18 e a $7^{\circ} \mathrm{C}$. Para $4{ }^{\circ} \mathrm{C}$, apenas foi observado um processo de adesão. A presença de $A$. hydrophila reduziu o desempenho de $S$. aureus. Nesta condição de cultivo multiespécie, apenas houve formação de biofilme a $18{ }^{\circ} \mathrm{C}$.

A. hydrophila, tanto em monocultivo quanto em presença de $S$. aureus, formou biofilme em todas as condições pesquisadas.

\section{Agradecimentos}

Agradecemos à coordenação de Aperfeicoamento de Pessoal de Nível superior, CAPES e à Fundação de Amparo à Pesquisa do Estado de Minas Gerais, FAPEMIG, ao apoio financeiro.

\section{Referências bibliográficas}

ALVES, E. Introdução à microscopia eletrônica de varredura. Lavras: UFLA, 2004. 43 p.

AMERICAN IRON AND STEEL INSTITUTE - AISI. Southfield: AISI, 2008. Disponível em: <http://www.steel.org>. Acesso em: Janeiro 2008.

ANDRADE, N. J.; BRIDGEMAN, T. A.; ZOTTOLA, E. A. Bacteriocidal activity of sanitizers against Enterococcus faecium attached to stainless steel as determined by plate count and impedance methods. Journal of Food Protection, v. 61, n. 7, p. 833-838, 1998.

ANDRÉ, M. C. D. P. B. et al. Comparison of Staphylococcus aureus isolates from food handlers, raw bovine milk and Minas Frescal cheese by antibiogram and pulsed-field gel electrophoresis following Smal digestion. Food Control, v. 19, n. 2, p. 200-207, 2008.

ARCURI, E. F. Biofilmes bacterianos na indústria de alimentos. Revista Leite e Derivados, v. 9, p. 40-45, 2000.

BANKS, M. K.; BRYERS, J. D. Bacterial species dominance within a binary culture biofilm. Applied and Environmental Microbiology, v. 57, n. 7, p. 1974-1979, 1991.

BOSSOLA, J. J.; RUSSELL, L. D. Electron microscopy. 2 ed. Boston: Jones and Bartlett, 1998. 670 p.

BRASIL. Ministério da Agricultura, Pecuária e Abastecimento. Instrução Normativa ${ }^{\circ} 51$, de 18 de Setembro de 2002. Aprova os regulamentos técnicos de produção, identidade e qualidade do leite tipo A, do leite tipo B, do leite tipo C, do leite pasteurizado e do leite cru refrigerado e o regulamento técnico da coleta de leite cru refrigerado e seu transporte a granel. Diário Oficial da República Federativa do Brasil, Poder Executivo, Brasília, DF, 18 de Setembro de 2002, Seção 1, p. 13. Disponível em: <http://www.agricultura.gov.br/>.

BRASIL. Ministério da Agricultura, Pecuária e Abastecimento. Portaria $n^{\circ}$ 146, de 07 de Março de 1996. Aprova os regulamentos técnicos de identidade e qualidade dos produtos lácteos. Diário Oficial da República Federativa do Brasil, Poder Executivo, Brasília, DF, 07 de Março de 1996, Seção 1, p. 3977. Disponível em: <http://www. agricultura.gov.br/>.

BRAUN, P.; SUTHERLAND, J. P. Predictive modelling of growth and measurement of enzymatic synthesis and activity by a cocktail of selected Enterobacteriaceae and Aeromonas hydrophila. International Journal of Food Microbiology, v. 105, n. 2, p. 257-266, 2005.
BRITISH STAINLESS STEEL ASSOCIATION - BSSA. Sheffield: BSSA, 2008. Disponível em: <http://www.bssa.org.uk>. Acesso em: Janeiro 2008.

BULHÕES, C. C. C.; ROSSI Jr., O. D. Ocorrência de bactérias do gênero Aeromonas em queijo-de-minas frescal artesanal. Arquivo Brasileiro de Medicina Veterinária e Zootecnia, v. 54, n. 3, p. 320-324, 2002.

CARNEIRO, M. S.; ROSSI Jr., O. D. Bactérias do gênero Aeromonas no fluxograma de beneficiamento do leite tipo A e seu comportamento frente à ação de antimicrobianos. Arquivos do Instituto Biológico, v. 73, n. 3, p. 271-276, 2006.

CHMIELEWSKI, R. A. N.; FRANK, J. F. Biofilm formation and control in food processing facilities. Comprehensive Reviews in Food Science and Food Safety, v. 2, n. 1, p. 22-32, 2003.

COSTERTON, J. W. et al. Microbial biofilmes. Annual Review of Microbiology, v. 49, p. 711-745, 1995.

DONLAN, R. M.; COSTERTON, J. W. Biofilms: survival mechanisms of clinically relevant microorganisms. Clinical Microbiology Reviews, v. 15, n. 2, p. 167-193, 2002.

DRENKARD, E. Antimicrobial resistance of Pseudomonas aeruginosa biofilms. Microbes and infection / Institut Pasteur, v. 5, n. 3, p. 1213-1219, 2003.

FLACH, J.; KARNOPP, C.; CORÇÃO, G. Biofilmes formados em matéria-prima em contato com confeites: fatores de virulência envolvidos. Acta Scientiae Veterinariae, v. 33, p. 291-296, 2005

FREITAS, A. C. et al. Occurrence and characterization of Aeromonas species in pasteurized milk in white cheese in Rio de Janeiro, Brazil. Journal of Food Protection, v. 56, n. 1, p. 62-65, 1993.

FUSTER-VALLS, N. et al. Effect of different environmental conditions on the bacteria survival on stainless steel surfaces. Food Control, v. 19, n. 3, p. 308-314, 2008.

HERRERA, J. J. R. et al. Adhesion and detachment kinetics of several strains of Staphylococcus aureus subsp. aureus under three different experimental conditions. Food Microbiology, v. 24, n. 6, p. 585-591, 2007.

HOOD, S. K.; ZOTTOLA, E. A. Growth media and surface conditioning influence the adherence of Pseudomonas fragi, Salmonella typhimurium and Listeria monocytogenes cells to stainless steel. Journal of Food Protection, v. 60, n. 9, p. 1034-1037, 1997.

JENKINSON, H. F.; LAPPIN-SCOTT, H. M. Biofilms adhere to stay. Trends in Microbiology, v. 9, n. 1, p. 9-10, 2001.

MANSFELD, F. The interaction of bacteria and metal surfaces. Electrochimica Acta, v. 52, n. 27, p. 7670-7680, 2007.

MARCHAND, S. et al. Selective determination of the heat-resistant proteolytic activity of bacterial origin in raw milk. International Dairy Journal. (no prelo).

MEYLHEUC, T. et al. Adsorption on stainless steel surfaces of biosurfactants produced by gram-negative and gram-positive bacteria: consequence on the bioadhesive behavior of Listeria monocytogenes. Colloids and Surfaces B: Biointerfaces, v. 52, n. 2, p. 128-137, 2006.

OLIVEIRA, M. Time course of biofilm formation by Staphylococcus aureus and Staphylococcus epidermidis mastitis isolates. Veterinary Microbiology, v. 124, n. 1-2, p. 187-191, 2007.

OULAHAL, N. et al. Quantitative analysis of survival of Staphylococcus aureus or Listeria innocua on two types of surfaces: polypropylene and stainless steel in contact with three different dairy products. Food Control, v. 19, n. 2, p. 178-185, 2008. 
PALUMBO, S. A. et al. Starch ampicillin agar for the quantitative detection of Aeromonas hydrophila. Applied Environmental Microbiology, v. 50, n. 4, p. 1027-1030, 1985.

POMPERMAYER, D. M. C.; GAYLARDE, C. C. The influence of temperature on the adhesion of mixed cultures of Staphylococcus aureus and Escherichia coli to polypropylene. Food Microbiology, v. 17, n. 4, p. 361-365, 2000.

RICKARD, A. H. et al. Bacterial coaggregation: an integral process in the development of multi-species biofilmes. Trends in Microbiology, v. 11, n. 2, p. 94-100, 2003.

RODE, T. M. et al. Different patterns of biofilm formation in Staphylococcus aureus under food-related stress conditions. International Journal of Food Microbiology, v. 116, n. 3, p. 372-383, 2007.

RONNER, A. B.; WONG, A. C. L. Biofilm development and sanitizer inactivation of Listeria monocytogenes and Salmonella typhimurium on stainless steel and buna-n rubber. Journal of Food Protection, v. 56, n. 9 , p. $750-758,1993$.

SAS Institute. SAS/ETS user's guide. Version 6. 2 ed. Cary: SAS Intitute, 1995.

SAWYER, L. K.; HERMANOWICZ, S. W. Detachment of biofilm bacteria due to variations in nutrient supply. Water Science and Technology, v. 37, p. 211-214, 1998.
SHENG, X.; TING, Y. P.; PEHKONEN, S. O. Force measurements of bacterial adhesion on metals using a cell probe atomic force microscope. Journal of Colloid and Interface Science, v. 310, n. 2, p. 661-669, 2007.

STOODLEY. P. et al. Biofilms as complex differentiated communities. Annual Review Microbiology, v. 56, p. 187-209, 2002.

TIRADO, C.; SCHIMDT, K. WHO surveillance programme for control of food-borne infections and intoxications: preliminary results and trends across greater. Europe Journal of Infection, v. 43, n. 1, p. 80-84, 2001.

VANDERZANT, C.; SPLITTSTOESSER, D. F. Compendium of methods for the microbiological examination of foods. 3 ed. Washington: American Public Health Association, 1992. 1219 p.

VANHAECKE, E. et al. Kinetics of Pseudomonas aeruginosa adhesion to 304 and 316-L stainless steel: role of cell surface hidrophobicity. Applied and Environmental Microbiology, v. 56, p. 788-795, 1990.

WIRTANEN, G.; HUSMARK, U.; MATTILA-SANDHOLM, T. Microbial evaluation of the biotransfer potencial from surfaces with Bacillus biofilms after rinsing and cleaning procedures in closed food-processing systems. Journal of Food Protection, v. 59, n. 7, p. 727-733, 1996. 